\title{
Indicadores geoquímicos de contaminação por compostos orgânicos voláteis em águas subterrâneas da Bacia do Rio Lucaia, Salvador, Bahia
}

\author{
Paula Gimenez Bezerra ${ }^{1}$, Joil José Celino ${ }^{2 *}$, Karina Santos Garcia ${ }^{1}$, Milena Rocha de Oliveira ${ }^{1}$
}

\begin{abstract}
Resumo Este trabalho investigou a contaminação das águas subterrâneas da bacia do Aquífero do Rio Lucaia, Salvador (BA), por hidrocarbonetos de petróleo oriundos do vazamento de tanques de combustível. As concentrações de benzeno, tolueno, etilbenzeno e xilenos - BTEX —, nitrato, sulfato e ferro (II) foram determinadas em 17 amostras de águas subterrâneas. A concentração de BTEX variou entre 0,2 e 185,7 $\mu \mathrm{g} . \mathrm{L}^{-1}$ e as concentrações de nitrato, sulfato e ferro (II) foram correlacionadas com os níveis de BTEX submetidos a degradação natural. Em apenas dois pontos os níveis de BTEX foram observados muito acima do permitido pela Resolução CONAMA nº 396/2008, enquanto os outros estavam abaixo do limite de detecção.
\end{abstract}

Palavras-chave: BTEX; águas subterrâneas; contaminação.

\begin{abstract}
Geochemical indicators of contamination by volatile organic compounds in groundwater on Lucaia's River Basin, Salvador, Bahia, Brazil. This work investigated the groundwater contamination of the Lucaia's River Basin, Salvador, Brazil, for petroleum hydrocarbons leaking from fuel tanks. The concentrations of benzene, toluene, ethylbenzene and xylenes - BTEX —, sulfate, nitrate and iron (II) was determined in 17 samples of groundwater. The concentration of BTEX ranged from 0.2 to $185.7 \mu \mathrm{g} . \mathrm{L}^{-1}$ and the concentrations of sulfate, nitrate and iron (II) were correlated with levels of BTEX undergoing natural degradation. In only two points BTEX levels were observed far above the permitted by CONAMA Resolution $n^{\circ} 396 / 2008$, while the others were below the detection limit.
\end{abstract}

Keywords: BTEX; groundwater; contamination.

INTRODUÇÃOO Os problemas mais graves de contaminação das águas subterrâneas são atribuídos aos hidrocarbonetos aromáticos, ocorrendo, na maioria dos casos, devido ao vazamento de tanques subterrâneos que armazenam combustíveis derivados de petróleo (Forte et al. 2007). Dentre os constituintes da gasolina, principal derivado do petróleo, os que merecem maior preocupação são os hidrocarbonetos voláteis monoaromáticos, benzeno, tolueno, etilbenzeno e xileno - BTEX - , devido a sua toxicidade e solubilidade em água (Corseuil \& Alvarez 1996). Esses compostos são grandes depressores do sistema nervoso central, podendo causar toxicidade crônica, mesmo que em pequenas concentrações. O benzeno, reconhecido como o mais tóxico dos BTEX, é comprovadamente uma substância carcinogênica, podendo causar leucemia se ingerida, mesmo em baixas concentrações e períodos não muito longos de tempo. Uma exposição aguda, ou seja, a altas concentrações e curtos períodos de tempo, por inalação ou ingestão, pode causar até mesmo a morte (Silva 2002). De acordo com o U.S. Environmental Protection Agency
(US EPA) há suficiente indicação que o benzeno é potencialmente carcinogênico, em estudos em animais e humanos. Trabalhadores expostos a altas concentrações de benzeno no ambiente de trabalho tiveram aumento na incidência de leucemia.

Muitos dos postos combustíveis da Bahia, segundo a Agência Nacional do Petróleo (ANP), foram instalados na década de 1970, nos quais grande parte dos tanques enterrados nos postos combustíveis é construída em aço, sem proteção contra corrosão, tendo em média uma vida útil de aproximadamente 25 anos (ANP 2004, Mariano 2006). Os padrões de qualidade para águas subterrâneas no Brasil estão previstos na Resolução n ${ }^{0}$ 396/2008 do CONAMA, em que a concentração máxima permitida para o benzeno, tolueno, etilbenzeno e xilenos é de 5, 24, 200 e $300 \mu \mathrm{g} . \mathrm{L}^{-1}$, respectivamente (Brasil, 2008).

No Brasil, a gasolina comercializada possui um percentual obrigatório de $25 \%$ de adição de álcool etílico anidro combustível (Brasil, 2006). O etanol adicionado adquire grande importância, pois sua presença altera o comportamento da gasolina em relação

\footnotetext{
${ }^{1}$ Núcleo de Estudos Ambientais, Instituto de Geociências, Universidade Federal da Bahia - UFBA, Salvador (BA), Brasil. E-mail: pagimbezerra@gmail.com,garciaks4@yahoo.com.br, milaoliver017@hotmail.com

${ }^{2}$ Programa de Pós-graduação Geoquímica: Petróleo e Meio Ambiente - POSPETRO, Instituto de Geociências, UFBA, Salvador (BA), Brasil.E-mail: joil@ufba.br

*Autor correspondente
} 
à solubilidade, mobilidade e degradação. Em eventos como estes, os compostos orgânicos de baixa solubilidade vão se dissolvendo gradualmente dependendo significativamente de sua densidade relativa à água (i.e., 1,0 kg.L-1) formando plumas de águas poluídas na direção do fluxo da água, contaminando todo o volume do aquífero. Líquidos menos densos que a água formam uma camada sobre a parte superior do lençol freático, incluindo-se a fração BTEX da gasolina, tornando-se agressores e grandes aliados ao processo de contaminação dos solos e dos mananciais (Craig, Rabideau, Suribhatlaet 2006, Li, Benson \& Lawson 2006, Hornig et al. 2008). Em sistemas subsuperficiais, os principais aspectos que podem afetar o comportamento dos BTEX em presença de etanol, segundo Corseuil e Fernandes (1999) são: o aumento da solubilidade dos BTEX em água pelo fenômeno de cossolvência e o aumento da mobilidade dos BTEX dissolvidos na água em presença de etanol, e o retardo da biodegradação natural dos BTEX, devido à preferência da microbiota pela degradação do etanol, o que aumenta a persistência desses compostos em água (Silva et al. 2002).

A análise e monitoramento de aquíferos em áreas urbanas sujeitos a contaminações por compostos derivados de petróleo, provenientes de vazamentos de tanques combustíveis, já é realizada em outras cidades do Brasil e do mundo, tornando-se necessário o estudo na bacia do Rio Lucaia, na cidade de Salvador (Bahia, Brasil), uma área densamente povoada (256 mil habitantes) e de elevada exposição aos agentes e fontes de contaminações antrópicas (Nascimento 2002, Silva et al. 2002, Rosell et al. 2003, Sandres 2004, Nascimento \& Barbosa 2005, Forte et al. 2007).

Ao realizar a coleta, manuseio ou armazenamento de amostras de água subterrânea, perdas incontroláveis dos compostos voláteis podem facilmente influenciar o resultado em uma ou mais ordens de grandeza. $\mathrm{Na}$ amostragem de água subterrânea, o método de amostragem por baixa-vazão $\left(<1 \mathrm{~L} \cdot \mathrm{min}^{-1}\right)$ possibilita a redução da perturbação causada ao aquífero por um bombeamento brusco, minimizando o revolvimento do solo e o isolamento da água, tornando assim as amostras mais representativas (Hewitt \& Myers 1999).

O processo de atenuação natural dos compostos derivados do petróleo consiste na redução de massa, concentração e mobilidade dos contaminantes na água subterrânea ao longo do tempo e distância do local de derramamento, devido a processos físico-químicos e biológicos naturais, podendo ocorrer em condições aeróbicas ou anaeróbicas. A biorremediação natural dos monoaromáticos é o método principal de degradação para esses compostos; estudos indicam que mais de $90 \%$ da remoção de BTEX através dessa abordagem deve-se ao processo de degradação natural (Farhadian et al. 2008). De um modo geral, os compostos orgânicos são oxidados por um composto aceptor, que é reduzido, através de uma reação de oxirredução. Na biodegradação aeróbia, o oxigênio dissolvido é o receptor de elétrons, sendo o aceptor preferencial dos microorganismos, devido ao maior ganho de energia nesse tipo de reação. $\mathrm{Na}$ degradação anaeróbia, os receptores de elétrons são o nitrato $\left(\mathrm{NO}^{3-}\right)$, o íon ferro (III), o sulfato ( $\mathrm{SO}_{4}^{2-}$ ), o manganês (IV), e o dióxido de carbono $\left(\mathrm{CO}_{2}\right)$, entre outros (Silva 2002, Nunes \& Corseuil 2007). Em aquíferos contaminados por compostos derivados de petróleo, as condições anaeróbicas são as principais vias de biodegradação, a depender da concentração presente de oxigênio dissolvido (Rouychoudhury \& Merrett 2006).

A Bacia do Rio Lucaia (Bahia, Brasil) é uma área densamente povoada e de elevada exposição aos agentes e fontes de contaminações antrópicas, constituindo um grave problema de saúde pública, com sérios riscos e efeitos adversos na população quando seus mananciais são utilizados para consumo doméstico (Nascimento 2002). O objetivo do presente trabalho foi avaliar e monitorar a contaminação das águas subterrâneas do aquífero da Bacia do Rio Lucaia por compostos orgânicos voláteis (BTEX), através de cacimbas, fontes e poços de postos, determinando o grau de comprometimento ambiental e sua atenuação por aceptores de elétrons.

MATERIAIS E MÉTODOS A área que corresponde à Bacia do Rio Lucaia (Fig. 1) localiza-se na capital do estado da Bahia, situada na porção leste. Tal região está compreendida entre os paralelos $12^{\circ} 58^{\prime} 48^{\prime \prime}$ e $13^{\circ} 00^{\prime} 58^{\prime \prime} \mathrm{S}$ e meridianos $39^{\circ} 32^{\prime} 05^{\prime \prime} \mathrm{W}$, apresentando aproximadamente $14 \mathrm{~km}^{2}$, sendo integrada parcialmente ou totalmente pelos seguintes bairros: Campinas de Brotas, Acupe de Brotas, Engenho Velho de Brotras, Itaigara, Rio Vermelho, Federação, Ondina, Tororó, Santa Cruz e Fazenda Garcia).

As águas subterrâneas que alimentam a Bacia do Rio Lucaia são provenientes de dois aquíferos sobrepostos (um raso e um fissural), cuja recarga ocorre 

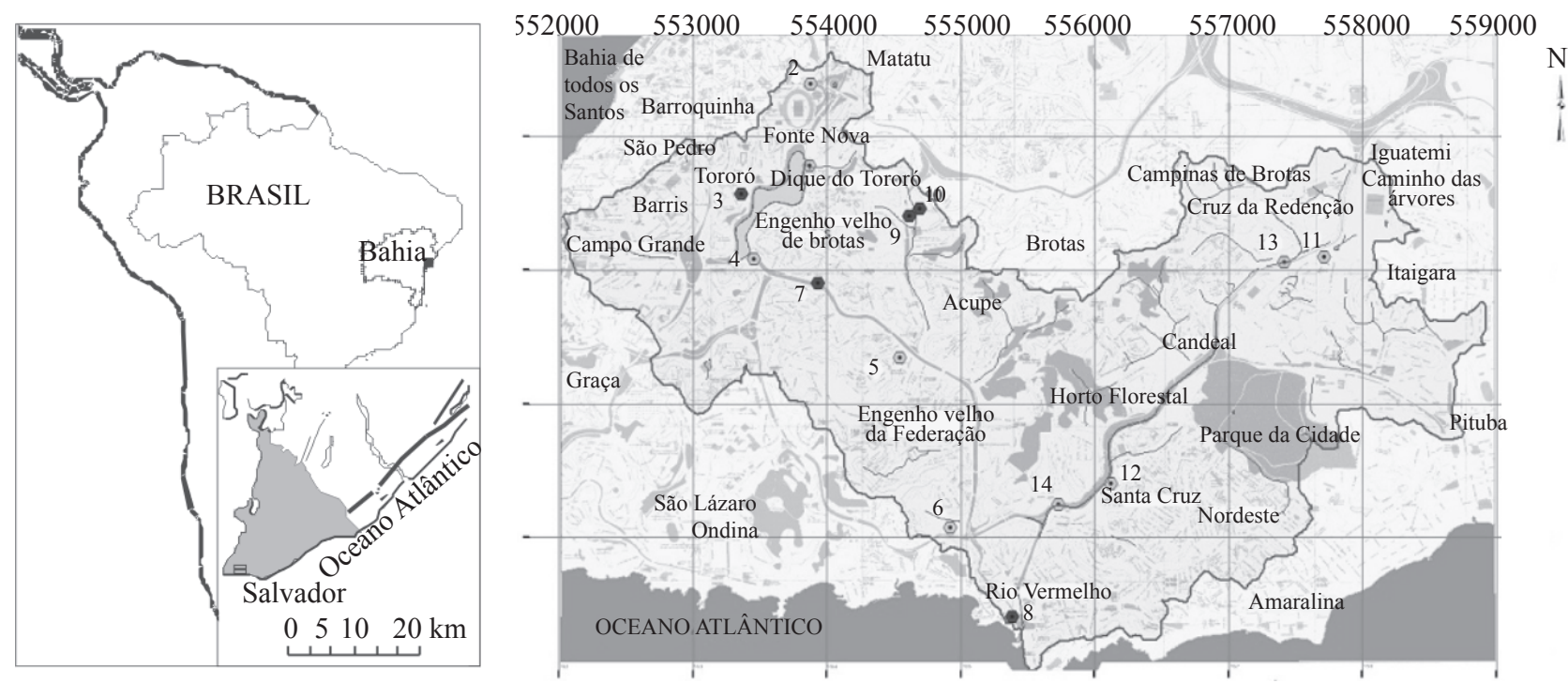

Figura 1 - Mapa de situação e localização da área estudada e dos pontos de amostragem na cidade de Salvador, Bahia.

por infiltração direta das chuvas ou dos escoamentos superficiais, logo possui alto risco de contaminação. O aquífero raso (superior) é composto por solos, pouco espessos, com níveis hidrostáticos, em sua maioria, de 2 a $3 \mathrm{~m}$. Assim, os poços existentes neste aquífero têm no máximo $10 \mathrm{~m}$ de profundidade. Este aquífero possui baixa capacidade de armazenamento de água devido a sua porosidade e pequena espessura, porém a descarga proveniente da produção dos poços é compensada pela recarga pluvial (alta pluviosidade no local) contínua durante todo o ano, mantendo o aquífero, praticamente em estado estacionário, ou seja, sem grandes alterações do nível de água (Nascimento 2002).

O outro aquífero é classificado como fissural, pois a água é armazenada e flui nas fraturas das rochas do embasamento cristalino, dispostas abaixo do solo. Este tipo de aquífero possui capacidade de armazenamento inferior ao primeiro e heterogênea, pois a capacidade é dependente da diferenciada distribuição da densidade de fraturamento no embasamento. Os poços confeccionados para produção de água neste aquífero possuem profundidade elevada, em torno de $52 \mathrm{~m}$ e, embora alguns produzam, também, do aquífero poroso acima, as vazões medidas nos poços evidenciam o baixo potencial hidrogeológico.

As amostras foram coletadas no período chuvoso, de 5 a 13 de julho de 2010, num total de 13 pontos entre poços e cacimbas rasos, medindo entre 8 e $10 \mathrm{~m}$ de profundidade, através de bomba peristáltica de baixa vazão Solinst (modelo 410) acoplada a uma célula de fluxo MicroPurge basics (modelo MP20) para amostragem de baixa vazão (low-flow sampling). Em campo, foram medidos os parâmetros físico-químicos na água: $\mathrm{pH}$, Eh, temperatura, condutividade e oxigênio dissolvido. Após essas medidas, as amostras foram acondicionadas de duas formas: em vials de vidro de $40 \mathrm{~mL}$ com tampa e septo de teflon, para determinação de BTEX, e em frascos de polietileno de $500 \mathrm{~mL}$, para a determinação de nitrato, sulfato e ferro (II), sendo preenchidos até a boca e sem bolhas e resfriados a $4^{\circ} \mathrm{C}$ até a chegada ao Laboratório de Estudos do Petróleo (LEPETRO) do Instituto de Geociências (IGEO) da Universidade Federal da Bahia (UFBA), onde foram analisadas no mesmo dia. As amostras coletadas nos frascos plásticos foram filtradas com filtro de acetato antes das determinações. A determinação do BTEX na água foi realizada utilizando a metodologia EPA $8260 \mathrm{C}$ e 5030C. As análises de compostos orgânicos voláteis em água foram realizadas através da técnica de purge and trap (P\&T), modelo 3100 da Tekmar, associada à cromatografia gasosa acoplada a espectrômetro de massas (CG-EM) com detector íon trap, respectivamente modelos CP-3800 e SATUM 2200, ambos da Varian. A quantificação dos compostos de interesse foi feita através do método de padronização interna, como recomenda a EPA.

A curva de calibração foi obtida a partir de um mix de padrão de BTEX em metanol, de concentração $2,0 \mathrm{mg} \cdot \mathrm{mL}^{-1}$, de onde foi preparada uma solução estoque de 10 ppm de BTEX, para a posterior 
diluição dos pontos da curvas, que variaram de 2 a $200 \mu \mathrm{g} . \mathrm{L}^{-1}$. Como padrão interno foi utilizada uma solução de clorobenzeno-d5 $100 \mu \mathrm{g} \cdot \mathrm{mL}^{-1}$, obtida através da diluição de um padrão de $5,0 \mathrm{mg} \cdot \mathrm{mL}^{-1}$. As diluições dos pontos da curva foram feitos em água ultrapura Milli-Q (Bezerra et al. 2011). Todos os padrões utilizados foram da marca AccuStandard. Para avaliar a homogeneidade das amostras nos pontos coletados, as mesmas foram analisadas em duplicatas e triplicatas, sendo 20 e $10 \%$ do total de amostras, respectivamente.

Em paralelo às análises de BTEX, foram realizadas as determinações de sulfato, através de kits da Hach, segundo método SulfaVer 4 com análise em espectrofotômetro de UV-VIS da Varian, modelo Cary 50 Probe, numa faixa de $450 \mathrm{~nm}$; de nitrato, utilizando-se kits Hach, segundo método NitraVer 5 e leitura em espectrofotômetro Cary, da Varian, numa faixa de $400 \mathrm{~nm}$; e de íon $\mathrm{Fe}^{2+}$ dissolvido, segundo método colorimétrico $3500-\mathrm{Fe} \mathrm{D}$, que consiste na reação do ferro solúvel com a 1,10-fenantrolina, formando um complexo alaranjado de intensidade de cor em proporção direta com a concentração de $\mathrm{Fe}^{2+}$, que foi lido posteriormente também em espectrofotômetro Cary, da Varian, numa faixa de $510 \mathrm{~nm}$ (Eaton, Clesceri \& Greenberg 1995).

Para o tratamento estatístico dos dados obtidos, foram utilizados os seguintes programas: InStat, da GraphPad, para o tratamento descritivo inicial; Statistica 7.0, Statsoft, para a análise de agrupamento (cluster) e Canoco 4.5, para a análise de ordenamento (redundância).

RESULTADOS E DISCUSSÃo Na Tab. 1 encontram-se os valores das coordenadas geográficas
(UTM), pH, Eh, temperatura, sólidos totais dissolvidos (STD), oxigênio dissolvido (O.D.), condutividade e nível estático dos poços coletados. Na Tab. 2 encontram-se as concentrações obtidas das análises, os valores citados na literatura e os valores reguladores no Brasil.

Analisando-se os resultados obtidos de BTEX nos 13 pontos coletados (Fig. 2), observa-se que em sua grande maioria os teores encontrados foram baixos, onde $62 \%$ das amostras coletadas apresentaram valores inferiores aos de limites de detecção do método (LDM). Somente dois pontos de coleta obtiveram um valor acima do indicado pelo CONAMA, referente ao benzeno, RIO $1\left(185,7 \mu \mathrm{g} . \mathrm{L}^{-1}\right)$ e VAS 3 $\left(9,8 \mu \mathrm{g} \cdot \mathrm{L}^{-1}\right)$.

Segundo Resolução do CONAMAn ${ }^{\circ}$ 396/2008, art. $3^{\circ}$, parágrafo IV, a água analisada enquadra-se como classe 3: águas dos aquíferos, conjunto de aquíferos ou porção desses, com alteração de sua qualidade por atividades antrópicas, para as quais não é necessário o tratamento em função dessas alterações, mas que podem exigir tratamento adequado, dependendo do uso preponderante, devido às suas características hidrogeoquímicas naturais.

Um estudo preliminar sobre o efeito da atenuação natural do BTEX foi realizado, tendo como parâmetros a concentração dos aceptores de elétrons $\mathrm{O}_{2}, \mathrm{NO}^{3-}, \mathrm{SO}^{2-}, \mathrm{Fe}^{3+}$, sendo que dessas espécies medidas, foi avaliada a concentração de $\mathrm{Fe}^{2+}$, que é a forma reduzida do aceptor $\mathrm{Fe}^{3+}$. Através de estudos estatísticos, nota-se que a variável Eh tem uma importância diferenciada das outras variáveis analisadas, assim como os pontos RIO 1, VAS 3 e OGU 1 (8, 7 e 9 , respectivamente) são diferenciados dos demais pontos amostrados, provavelmente devido às suas

Tabela 1 - Localização e parâmetros fisico-químicos obtidos nos poços da bacia do Rio Lucaia

\begin{tabular}{|c|c|c|c|c|c|c|c|c|c|c|}
\hline Ponto & Sigla & UT & & $\mathrm{pH}$ & Eh $(\mathrm{mV})$ & Temperatura $\left({ }^{\circ} \mathrm{C}\right)$ & $\begin{array}{l}\text { STD } \\
\left(\text { g.L } L^{-1}\right)\end{array}$ & $\begin{array}{c}\text { O.D. } \\
\left(\mathrm{mg} . \mathrm{L}^{-1}\right)\end{array}$ & $\begin{array}{l}\text { Condutividade } \\
\left(\mathrm{mS} . \mathrm{cm}^{-1}\right)\end{array}$ & $\begin{array}{c}\text { Nível } \\
\text { estático (m) }\end{array}$ \\
\hline 1 & DIQ 1 & 8564759 & 553887 & 8,85 & 13,00 & 25,40 & 0,40 & 6,08 & 0,61 & 0,58 \\
\hline 2 & DIQ 2 & 8565379 & 553881 & 5,87 & 13,00 & 25,62 & 0,30 & 6,42 & 0,40 & 0,35 \\
\hline 3 & DIQ 3 & 8564570 & 553359 & 5,51 & 3,00 & 25,76 & 0,30 & 4,99 & 0,64 & 1,07 \\
\hline 4 & DIQ 4 & 8564088 & 553467 & 6,55 & 68,00 & 27,14 & 0,40 & 3,41 & 0,34 & 0,28 \\
\hline 5 & VAS 1 & 8563333 & 554555 & 5,22 & 15,00 & 26,95 & 0,30 & 4,98 & 0,48 & 3,18 \\
\hline 6 & VAS 2 & 8562067 & 554929 & 5,18 & 8,00 & 28,02 & 0,30 & 4,39 & 0,50 & 1,84 \\
\hline 7 & VAS 3 & 8563893 & 553941 & 5,84 & $-55,00$ & 27,26 & 0,30 & 4,19 & 0,41 & 0,35 \\
\hline 8 & RIO 1 & 8561390 & 555391 & 5,93 & $-145,00$ & 30,39 & 0,60 & 2,52 & 0,89 & 3,00 \\
\hline 9 & OGU 1 & 8564400 & 554615 & 5,80 & $-35,00$ & 25,61 & 0,30 & 5,78 & 0,48 & 1,40 \\
\hline 10 & OGU 2 & 8564423 & 554662 & 3,87 & 40,00 & 25,89 & 0,30 & 3,95 & 0,47 & 2,88 \\
\hline 11 & ACM 2 & 8563894 & 553943 & 5,25 & 35,00 & 28,83 & 0,30 & 3,42 & 0,43 & 4,33 \\
\hline 12 & ACM 3 & 8564043 & 557751 & 4,99 & 33,00 & 28,15 & 0,40 & 5,19 & 0,55 & 4,00 \\
\hline 13 & $\mathrm{ACM} 4$ & 8562399 & 556151 & 4,53 & 121,00 & 26,47 & 0,20 & 4,77 & 0,38 & 2,83 \\
\hline
\end{tabular}

SDT: sólidos totais dissolvidos; O.D.: oxigênio dissolvido. 
Tabela 2 - Valores obtidos comparados à literatura e ao Conselho Nacional do Meio Ambiente

\begin{tabular}{|c|c|c|c|c|c|}
\hline $\begin{array}{l}\text { Parâmetros } \\
\text { analisados }\end{array}$ & $\begin{array}{l}\text { Concentrações } \\
\text { obtidas }\end{array}$ & Silva et al. (2002) & $\begin{array}{l}\text { Nascimento \& } \\
\text { Barbosa (2005) }\end{array}$ & $\begin{array}{l}\text { Ministério da Saúde } \\
\text { (2004) }\end{array}$ & CONAMA (2008) \\
\hline Benzeno $\left(\mu \mathrm{g} . \mathrm{L}^{-1}\right)$ & $0,6-185,7$ & $509,0-521,0$ & - & 5 & 5 \\
\hline Tolueno $\left(\mu \mathrm{g} . \mathrm{L}^{-1}\right)$ & $0,4-11,3$ & $14,0-17,0$ & - & 170 & 24 \\
\hline Etilbenzeno $\left(\mu \mathrm{g} . \mathrm{L}^{-1}\right)$ & $0,2-16,9$ & 3,2 & - & 200 & 200 \\
\hline Xilenos $\left(\mu \mathrm{g} \cdot \mathrm{L}^{-1}\right)$ & $0,3-10,9$ & $17,0-85,0$ & - & 300 & 300 \\
\hline O.D. $\left(\mathrm{mg} \cdot \mathrm{L}^{-1}\right)$ & $2,5-6,4$ & $1,6-4,2$ & $0,4-6,4$ & $>6$ & - \\
\hline Sulfato (mg. $\left.\mathrm{L}^{-1}\right)$ & $4,5-86,8$ & $5,0-22,0$ & $4,1-59,4$ & 250 & 5 \\
\hline Nitrato $\left(\mathrm{mg} \cdot \mathrm{L}^{-1}\right)$ & $0,03-8,42$ & $1,0-8,0$ & $1,3-41,0$ & 10 & 0,3 \\
\hline $\mathrm{Fe}^{2+}\left(\mathrm{mg} \cdot \mathrm{L}^{-1}\right)$ & 0,47 & $<0,2$ & $16-5.480^{*}$ & $0,3 *$ & $0,3^{*}$ \\
\hline
\end{tabular}

* concentração de ferro total

CONAMA: Conselho Nacional do Meio Ambiente; O.D.: oxigênio dissolvido.

características de maior contaminação (Figs. 3 e 4). A significância de cada variável ambiental obtida foi testada estatisticamente e observa-se na Fig. 5 que as mais significativas no ambiente com presença dos analitos foram o Eh, o ferro (II), a condutividade, os sólidos totais dissolvidos e a temperatura. Foi encontrada uma relação extremamente significativa entre os compostos BTEX e o Eh e $\mathrm{Fe}^{2+}$, na qual se observa que quanto menor o valor do Eh, mais favorecida é a presença e degradação dos BTEX, que é diretamente proporcional aos valores encontrados de $\mathrm{Fe}^{2+}$, sendo um dos indícios do consumo de $\mathrm{Fe}^{3+}$ na degradação dos compostos. Assim, no ponto mais crítico de coleta (RIO 1), onde foi encontrado um teor igual a $185,7 \mu \mathrm{g} . \mathrm{L}^{-1}$ de benzeno, também foi encontrado 0,47 mg. $\mathrm{L}^{-1}$ de $\mathrm{Fe}^{2+}$, o dobro do teor encontrado por Silva et al. (2002), após uma avaliação da qualidade da água de poços residenciais do Rio de Janeiro, quanto à presença BTEX após dois anos da ocorrência de um vazamento de gasolina do tanque de armazenamento de combustível.

$\mathrm{Na}$ Tab. 1, os pontos com os valores mais negativos de Eh correspondem aos pontos com maior concentração de BTEX: VAS 3, RIO 1 e OGU 1, respectivamente. O ponto OGU 1 é intermediário aos dois grupos, poços contaminados e poços não contaminados, pois, apesar de apresentar teores de BTEX abaixo dos valores reguladores, suas características estão mais próximas aos poços com contaminação do que com os outros, como mostra a Fig. 4.

Quanto aos valores dos aceptores de elétrons, a ordem de degradação dos BTEX energeticamente favorável é o oxigênio $\left(\mathrm{O}_{2}\right)$, nitrato $\left(\mathrm{NO}^{3-}\right)$, íon ferro (III), o sulfato $\left(\mathrm{SO}_{4}{ }^{2-}\right)$, nessa ordem. Observa-se que os valores de $\mathrm{O}_{2}$ dissolvido $\left(3,4\right.$ a $\left.6,4 \mathrm{mg} . \mathrm{L}^{-1}\right)$ e de $\mathrm{NO}^{3-}\left(0,03\right.$ a $\left.8,42 \mathrm{mg} . \mathrm{L}^{-1}\right)$ encontram-se em níveis moderados, estando de acordo com o encontrado

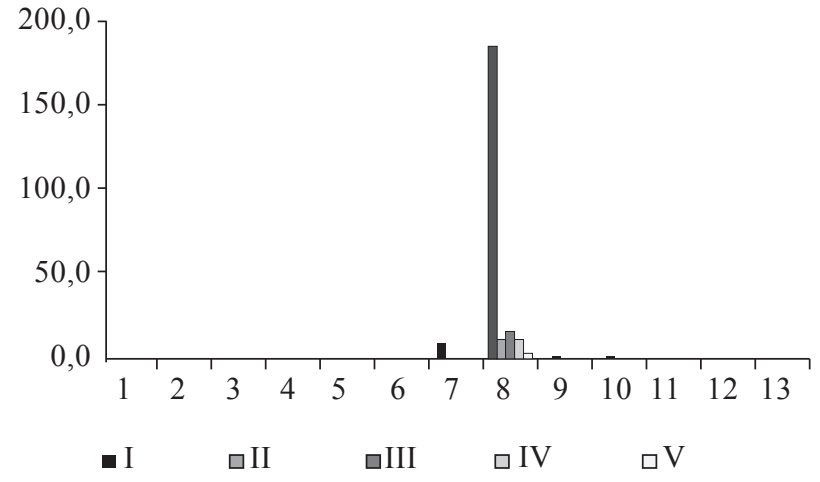

Figura 2 - Concentração de benzeno, tolueno, etilbenzeno e xilenos, em $\mu g \cdot L^{-1}$, nos pontos coletados na bacia do Rio Lucaia, em julho de 2010. I: benzeno; II: tolueno; III: etilbenzeno; IV: $m+p-$ xileno; V: o-xileno; 1: DIQ 1; 2: DIQ 2; 3: DIQ 3; 4: DIQ 4; 5: VAS 1; 6: VAS 2; 7: VAS 3; 8: RIO 1; 9: OGU 1; 10: $O G U$ 2; 11: ACM 2; 12: ACM 3; 13: $A C M 4$.

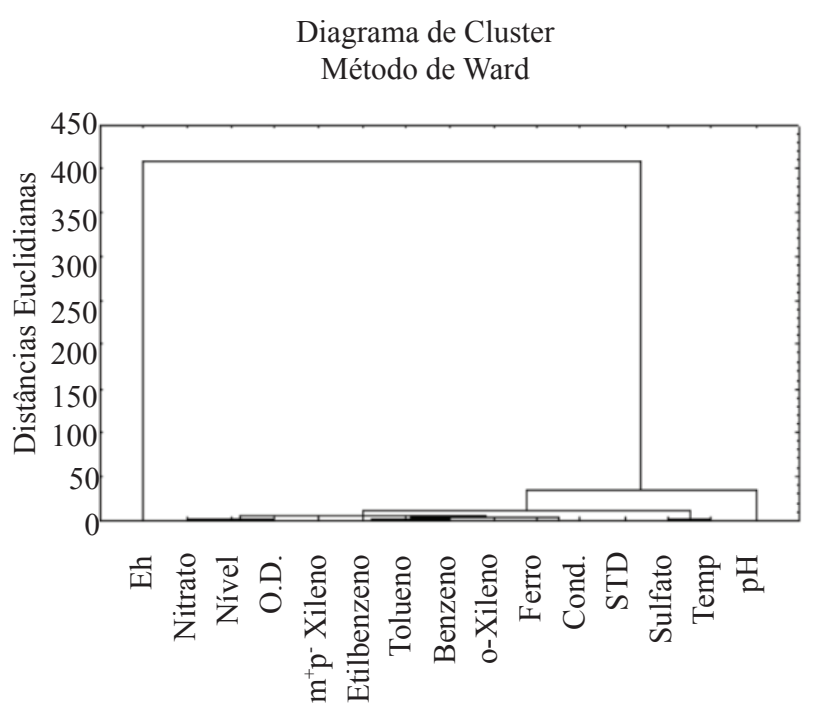

Figura 3 - Dendrograma representando o agrupamento das variáveis obtidas nos poços localizados na bacia do Rio Lucaia (BA). 


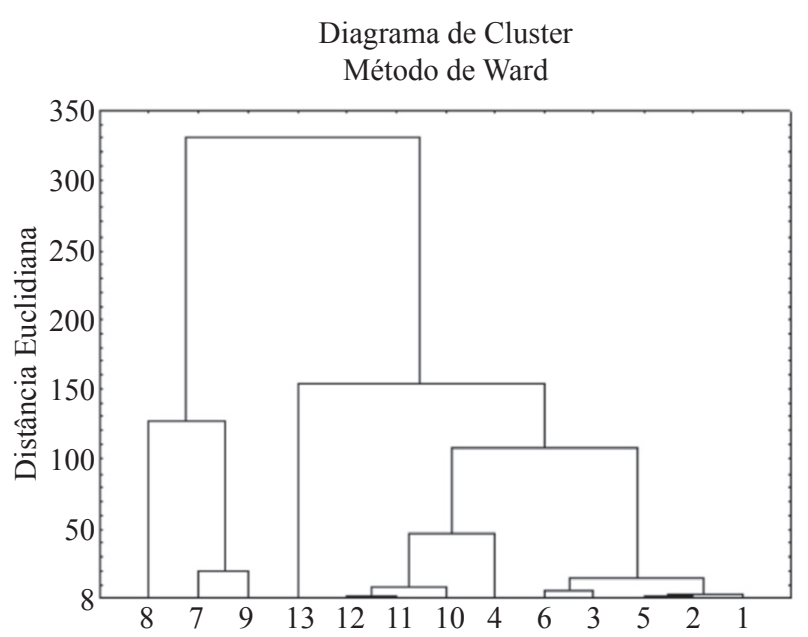

Figura 4 - Dendrograma representando o agrupamento dos poços coletados na bacia do Rio Lucaia (BA).

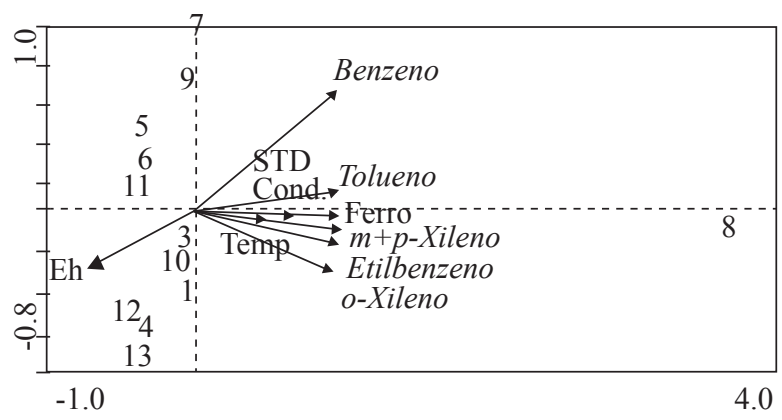

Figura 5 - Diagrama de ordenação representando a relação das variáveis com benzeno, tolueno, etilbenzeno e xilenos e os pontos de coleta.

por Silva et al. (2002). Comparando-se os valores de $\mathrm{NO}^{3-}$ com os valores obtidos por Nascimento $\&$ Barbosa (2005), na mesma área de estudo, nota-se que os valores diminuíram, estando também os valores de $\mathrm{O}_{2}$ em concordância. Já os valores de $\mathrm{SO}_{4}{ }^{2-}$ obtidos estão acima do que os encontrados nos dois trabalhos.

Em sua grande maioria, os hidrocarbonetos de petróleo são biodegradáveis sob condições aeróbicas. $\mathrm{O} \mathrm{O}_{2}$ é um cossubstrato que pode ter iniciado o mecanismo de biodegradação e, depois do metabolismo ter se iniciado, pode também funcionar como aceptor de elétron, gerando energia. Porém, a baixa solubilidade do $\mathrm{O}_{2}$ em água torna-se a maior limitação da biodegradação aeróbica na subsuperfície. Em altas concentrações de hidrocarboneto, esse tipo de biodegradação pode não ser suficiente para consumi-los completamente. Assim, quando o
$\mathrm{O}_{2}$ é esgotado e o $\mathrm{NO}^{3-}$ está presente, os microorganismos anaeróbicos facultativos utilizarão o $\mathrm{NO}^{3-}$ como aceptor final de elétron em substituição ao $\mathrm{O}_{2}$ (Borden, Gomez, Becker 1995). Analisando em conjunto as concentrações de BTEX, $\mathrm{O}_{2}$ dissolvido e $\mathrm{NO}^{3-}$, pode-se concluir que, provavelmente, houve atenuação natural por estes dois aceptores de elétron, iniciando-se com o $\mathrm{O}_{2}$, porém, sendo sustentado pelo $\mathrm{NO}^{3-}$, e, possivelmente, iniciando-se o consumo também de ferro (III), indicado nos pontos de maior concentração de benzeno. Os teores de $\mathrm{SO}_{4}{ }^{2-}$ são relativamente altos, indicando que este aceptor não foi utilizado no processo de biodegradação.

\section{CONCLUSÃO A disponibilidade tanto de} ferro (III) quanto de $\mathrm{NO}^{3-}$ (aceptores de elétron) nos aquíferos da Bacia do Rio Lucaia provavelmente contribuiu para a ocorrência da atenuação natural, sobretudo anaeróbica, dos BTEX (biodegradação) no sítio de estudo. A concentração de benzeno, acima de 30 vezes maior que a permitida pelo CONAMA, indica que este hidrocarboneto aromático, tóxico, está presente em altas concentrações no local.

Os poços com maior índice de contaminação estão localizações no bairro do Rio Vermelho e na avenida Vasco da Gama, ou seja, suas águas são inadequadas para consumo da população, já que propiciam risco ao desenvolvimento de doenças como o câncer. Devem ser dados esclarecimentos à população próxima dos locais estudados acerca do perigo de consumir água de poço sem avaliação precisa e confiável.

É importante que o monitoramento da água de poço, ministrado pela distribuidora responsável pelo posto, deve ser acompanhado pelo órgão público competente sobre o assunto para fiscalizar e avaliar sua qualidade, protegendo a população local de possíveis agressões à saúde.

AGRADECIMENTOS Este trabalho é um reflexo do apoio financeiro concedido pela Fundação de Amparo à Pesquisa do Estado da Bahia (FAPESB) através do termo de outorga $\mathrm{n}^{\mathrm{o}}$ APR0365/2008, Edital 005/2007, Pedido $\mathrm{n}^{\circ} 8.657 / 2007$, e pelo financiamento das análises laboratoriais através do CTPETRO/FAPEX/ PETROBRAS/CNPq ( ${ }^{\circ}$ 2201074500), Agência Nacional de Petróleo (ANP). 


\section{Referências}

AGÊNCIA NACIONAL DO PETRÓLEO (ANP). Anuários estatísticos, 2003. Disponível em: http:// www.anp.gov.br/?pg=8972. Acessado em: 01/10/2012.

Bezerra P.G., Celino J.J., Garcia K.S., Oliveira M.R. 2011. Validação de método cromatográfico acoplado ao purge and trap para análises ambientais. Cadernos de Geociências UFBA, 8:47-53.

Borden R.C., Gomez C.A., Becker M.T. 1995. Geochemical indicators of intrinsic bioremediation. Groundwater, 33:180-189.

BRASIL. Ministério da Agricultura, Pecuária e Abastecimento. Portaria ministerial $\mathrm{n}^{\circ}$ 51, de 22 de fevereiro de 2006. Fixa em vinte e cinco por cento o percentual obrigatório de adição de álcool etílico anidro combustível à gasolina e revoga a portaria $\mathrm{n}^{\circ} 278$, de 10 de novembro de 2006 . Diário Oficial da União de 29 de junho de 2007. Disponível em: http://sistemasweb.agricultura.gov.br/sislegis/action/ detalhaAto.do?method=consultarLegislacaoFederal Acessado em: 01/10/2012.

BRASIL. Ministério do Meio Ambiente. Portaria ministerial $n^{\circ} 396$, de 3 de abril de 2008. Diário Oficial da União de 07 de abril de 2008, seção I, p 64-68. Disponível em: http:/www.mma.gov.br/port/conama/ legiabre.cfm?codlegi=562. Acessado em: 10/11/2009.

Corseuil H.X. \& Alvarez P.J.J. 1996. Natural biorremediation perspective for BTX - contamined groundwater in Brazil: Effect of ethanol. Water Research, 34(7-8):311-318.

Corseuil, H.X. \& Fernandes, M. 1999. Efeito do Etanol no Aumento da Solubilização de Compostos Aromáticos Presentes na Gasolina Brasileira. Engenharia Sanitária e Ambiental, 4(1-2):71-75.

Craig J.R., Rabideau A.J., Suribhatlaet R. 2006. Analytical expressions for the hydraulic design of continuous permeable reactive barriers. Advances in Water Resources, 29:99-111.

Eaton A.D., Clesceri L.S., Greenberg A. E. 1995. Standard methods: examination of water and wastewater. The American Public Health Association, 19. ed. Washington, USA.

Farhadian M., Vachelard C., Duchez D., Larroche, C. 2008. In situ bioremediation of monoaromatic pollutants in groundwater: a review. Bioresource Technology, 99:5296-5308.

Forte E.J., Azevedo M.S., Oliveira R.C., Almeida R. 2007. Contaminação de aqüífero por hidrocarbonetos: estudo de caso na Vila Tupi, Porto Velho - Rondônia. Química Nova, 30(7):1539-1544.

Hewitt A.D. \& Myers K.F. 1999 Sampling and On-Site Analytical Methods for Volatiles in Soil and Groundwater: Field Guidance Manual. Relatório Especial 99-16 do US Army Corps of Engineers: Cold Regions Research \& Engineering Laboratory. Hanover.

Hornig G, Northcott K., Snape I., Stevens G. 2008. Assessment of sorbent materials for treatment of hydrocarbon contaminated ground water in cold regions. Cold Regions Science and Technology, 53:83-91.
Li L., Benson C.H., Lawson E.M. 2006. Modeling porosity reductions caused by mineral fouling in continuous-wall permeable reactive barriers. Journal of Contaminant Hydrology, 83:89-121.

Mariano A.P. 2006. Avaliação do potencial de biorremediação de solos e de águas subterrâneas contaminados com óleo diesel. Dissertação de Doutorado Profissional em Geociências e Meio Ambiente, Universidade Estadual Paulista, Rio Claro. 147 p.

Nascimento S.A.M. 2002. Estudo da qualidade da água do aqüifero freático nas bacias dos rios Lucaia e Baixo Camurujipe. Relatório Final Convênio UFBA/Embasa/ Fapex. Instituto de Geociências. Universidade Federal da Bahia. Salvador. Disponível em: http://www.nehma. ufba.br/projetos/Lucaia_Relatorio_Final.zip. Acessado: 07/04/2010.

Nascimento S.A.M., Barbosa J.S.F. 2005. Qualidade da água do aquífero freático no alto cristalino de Salvador, Bacia do Rio Lucaia, Salvador, Bahia. Revista Brasileira de Geociências, 35(4):543-550.

Nunes C.C. \& Corseuil H.X. 2007. Importância do etanol na atenuação natural de águas subterrâneas impactadas por gasolina. Revista de Engenharia Sanitária Ambiental, 12(3):259-265.

Rosell M., Lacorte S., Ginebreda A., Barceló D. 2003. Simultaneous determination of methyl tert.-butyl ether and its degradation products, other gasoline oxygenates and benzene, toluene, ethylbenzene and xylenes in Catalonian groundwater by purge-and-trapgas chromatography-mass spectrometry. Journal of Chromatography A, 995:171-184.

Rouychoudhury A.N. \& Merrett G.L. 2006. Redox pathways in a petroleum contaminated shallow sandy aquifer: Iron and sulfate reductions. Science of the Total Environment, 366:262-274.

Sandres G.C. 2004. Contaminação dos solos e águas subterrâneas provocada por vazamentos de gasolina nos postos de combustíveis devido à corrosão em tanques enterrados. Dissertação de Mestrado Profissional em Sistemas de Gestão, Universidade Federal Fluminense, Niterói. 147 p.

Silva R.L.B. 2002. Contaminação de poços rasos no bairro Brisamar, Itaguaí, RJ, por derramamento de gasolina: concentração de BTEX e avaliação da qualidade da água consumida pela população. Dissertação de Doutorado em Ciências da Saúde Pública), Escola Nacional de Saúde Pública da Fundação Oswaldo Cruz. Rio de Janeiro. 182 p.

Silva R.L.B., Barra C.M., Monteiro T.C.N., Brilhante O.M. 2002. Estudo da contaminação de poços rasos por combustíveis orgânicos e possíveis conseqüências para a saúde pública no Município de Itaguaí, Rio de Janeiro, Brasil. Cadernos de Saúde Pública, 18(6):1599-1607. 